\title{
The Demographic Transformation of Post-Socialist Countries
}

\author{
Causes, Consequences, and Questions \\ Elizabeth Brainerd*
}

February 2010

\begin{abstract}
The formerly socialist countries of Eastern Europe and the former Soviet Union have experienced a remarkable demographic transformation in the past twenty years. On many dimensions of fertility and family formation, much of the region now looks like Western Europe-below-replacement fertility rates, rising age at first marriage and first birth, and high and increasing out-of-wedlock birthrates, characterize many countries formerly distinguished by replacement-level fertility and early, near-universal marriage and childbearing. The other facet of this demographic transformation is nearly unprecedented changes in adult mortality rates. An upsurge of cardiovascular and external cause mortality caused a massive premature loss of life among working-age men in the former Soviet Union in the 1990s. In contrast, cardiovascular mortality has fallen at a rapid rate across Eastern Europe since 1989. This study discusses the dimensions and most likely causes of these demographic changes and assesses the possible consequences of the changing fertility and mortality patterns. Much remains unknown about the underlying reasons for the demographic transformation of the region; directions for future research in this area are discussed.
\end{abstract}

Keywords: fertility, marriage, mortality, transitional economies

JEL classification: J11, J13, P36

Copyright (C) UNU-WIDER 2010

*Brandeis University, CEPR, IZA, and WDI

This study has been prepared for the UNU-WIDER conference Reflections on Transition: Twenty Years after the Fall of the Berlin Wall, directed by Gérard Roland.

UNU-WIDER acknowledges the financial contribution to the conference by the Finnish Ministry for Foreign Affairs and the continued support to the research programme by the governments of Denmark (Royal Ministry of Foreign Affairs), Finland (Ministry for Foreign Affairs), Sweden (Swedish International Development Cooperation Agency-Sida) and the United Kingdom (Department for International Development). 


\section{Acknowledgements}

This study was prepared for the UNU-WIDER conference Reflections on Transition: Twenty Years after the Fall of the Berlin Wall, Helsinki, 18-19 September 2009. The author thanks Giovanni Andrea Cornia, Mario Nuti, Vladimir Popov, Gérard Roland, Daniel Treisman, and conference participants for helpful comments and suggestions.

The World Institute for Development Economics Research (WIDER) was established by the United Nations University (UNU) as its first research and training centre and started work in Helsinki, Finland in 1985. The Institute undertakes applied research and policy analysis on structural changes affecting the developing and transitional economies, provides a forum for the advocacy of policies leading to robust, equitable and environmentally sustainable growth, and promotes capacity strengthening and training in the field of economic and social policy making. Work is carried out by staff researchers and visiting scholars in Helsinki and through networks of collaborating scholars and institutions around the world.

www.wider.unu.edu publications@wider.unu.edu

UNU World Institute for Development Economics Research (UNU-WIDER)

Katajanokanlaituri 6 B, 00160 Helsinki, Finland

Typescript prepared by Lorraine Telfer-Taivainen at UNU-WIDER

The views expressed in this publication are those of the author(s). Publication does not imply endorsement by the Institute or the United Nations University, nor by the programme/project sponsors, of any of the views expressed. 


\section{Introduction}

In May 2006 Russian leader Vladimir Putin announced a radical new package of pronatalist policies designed to halt, and possibly reverse, the steep decline in Russia's birthrate over the past 15 years. The package included increased child benefits, longer maternity leaves, and a payment of over US $\$ 9,000$ to each woman who has a second child. While economists and demographers have long debated the efficacy of such pronatalist government policies in raising birthrates, the intention of this package of measures was clear - to stop the large declines in population that have affected Russia since the early 1990s.

The abrupt fall in fertility in Russia during the transition from socialism is not unique: virtually every country in Eastern Europe (EE) and the former Soviet Union (FSU) experienced significant declines in birthrates in the 1990s, and depressed levels of fertility continued in many countries well into the 2000s. Many countries also recorded a dramatic increase in mortality in the early 1990s; when combined with declining fertility, this led to significant population declines across the region since the start of transition, particularly in the countries of the FSU.

This study reviews these changes in fertility, family formation and mortality in EE and the FSU during the transition period, and discusses what is currently known about the causes of the demographic processes that have been underway in the region since 1989. As will be evident, the demographic transformation of the region has been remarkable in its speed and scope. Many East European countries now resemble Western Europe in their fertility and marriage patterns, and, after decades of low and stagnant levels of life expectancy under socialism, are now recording rapid gains in life expectancy to levels nearly convergent with those of the West. This demographic transformation has progressed more slowly in the FSU but appears to be well underway nevertheless. The changes in fertility and mortality documented here will likely have far-reaching consequences for each country's population size and age structure, and may influence the region's long-term economic growth prospects. The study concludes with a discussion of some of the possible consequences of this fundamental transformation of society in post-socialist countries. 1

\section{Fertility and family formation}

\subsection{Changes in birth rates by age and marital status}

The formerly socialist countries were characterized by a distinctive pattern of fertility and family formation-marriage and childbearing took place at relatively young ages (compared with Western Europe) and were near-universal. In Russia, for example, the average age at first marriage for women in 1989 was 22.1 years, compared with 25.3 in France. Rates of childlessness were near the biological limit of about 5 per cent; in the 1989 census, only 8 per cent of Russian women aged 40 to 49 had not had children. Aside from some of the less-developed republics of the USSR with high fertility levels,

\footnotetext{
${ }^{1}$ Albania, Tajikistan, Turkmenistan and the countries of former Yugoslavia are excluded from the analysis due to data limitations.
} 
in all other transition countries fertility rates had stabilized at about the replacement level of fertility (2.1 children per woman) in the period from 1965 to 1989 . As is well known, in many countries abortion rates were high, with abortion being used as the primary means of birth control in many countries of the FSU.

All of these patterns have changed markedly since the start of the transition. As noted above, virtually every country in EE and the FSU experienced a steep decline in fertility beginning in the late 1980s or early 1990s. This is illustrated in Figure 1, which shows the total fertility rate (TFR) in selected countries since 1970.2 The TFR declined to well below the replacement rate in many countries in the early years of the transition, and the pattern is remarkably similar across countries. In fact, fertility levels in Bulgaria (TFR of 1.09 in 1997) and Ukraine (TFR of 1.086 in 2001) fell below the lowest fertility level ever recorded in a European country during peacetime, that of Spain in 1997, with a total fertility rate of 1.10 . Fertility rates have increased slightly in most countries in recent years, but remain depressed both historically and in comparison with other developed countries.

Figure 1: Total fertility rate, selected countries

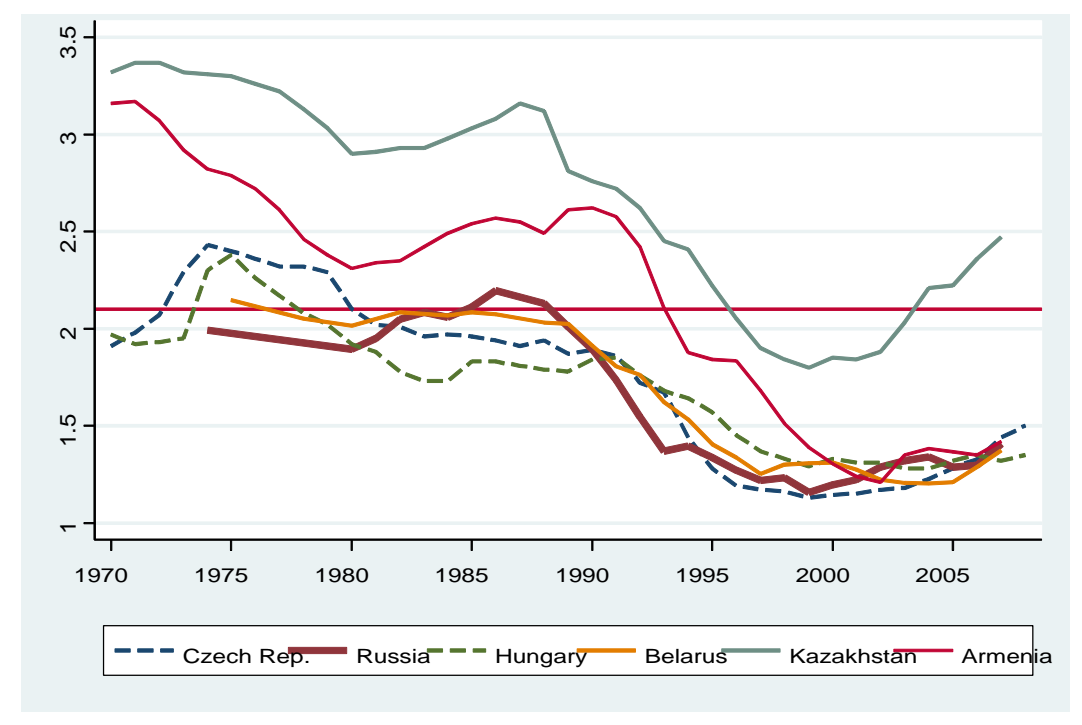

Demographers have argued that two distinctive fertility patterns have emerged in the region-a rapid shift toward later (first) childbearing that characterizes EE, and continued early and near-universal first births in the FSU (particularly Russia and Ukraine) but with the postponement of second- and higher-order births. 3 However, recent data (discussed below) indicate that, while fertility patterns shifted several years earlier and more dramatically in EE than in the FSU, the countries of the former USSR appear to be moving toward later childbearing and marriage as well.

\footnotetext{
${ }^{2}$ The total fertility rate is calculated based on current age-specific birth rates and represents the average number of children a woman can be expected to have during her lifetime. The fertility and mortality data used in this study are from the most recent national statistical or demographic yearbooks published by each country. When such data are missing, data from the TransMONEE database (www.transmonee.org), the WHO Health for All database (www.euro.who.int/HFADB), or the WHO Mortality database www.euro.who.int/InformationSources/Data/20011017_1 are used.

${ }^{3}$ See, for example, Kharkova and Andreev (2000), Sobotka (2003), Barkalov (2005), and Perelli-Harris (2005, 2006).
} 
Figure 2a: Age-specific birth rates, Russia

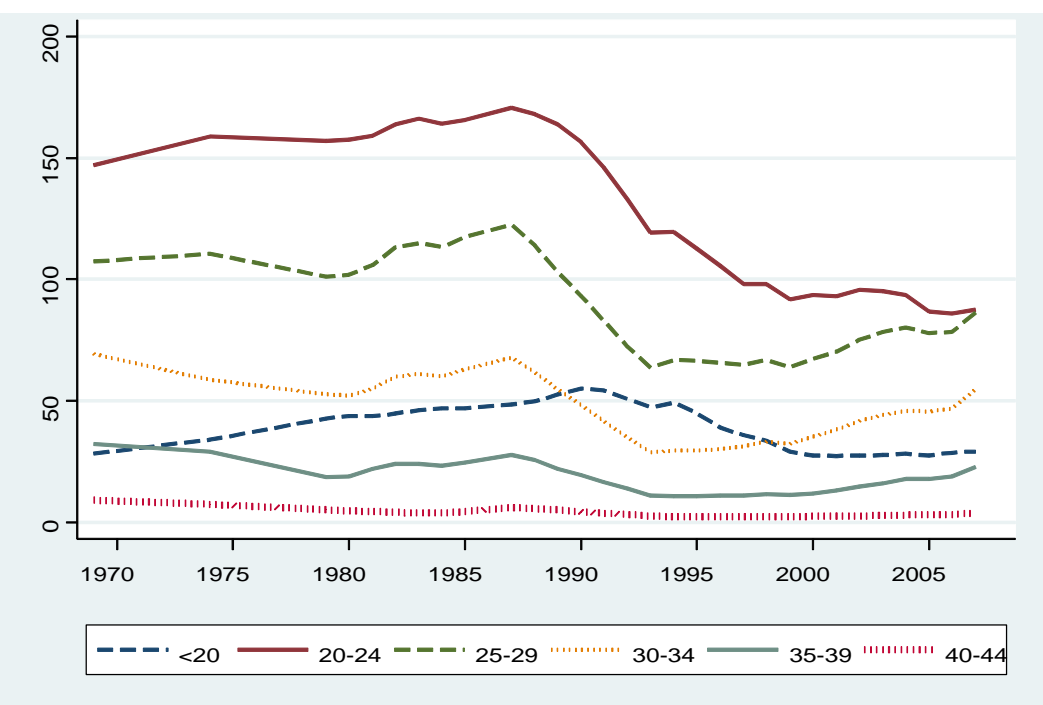

Figure 2b: Age-specific birth rates, Hungary

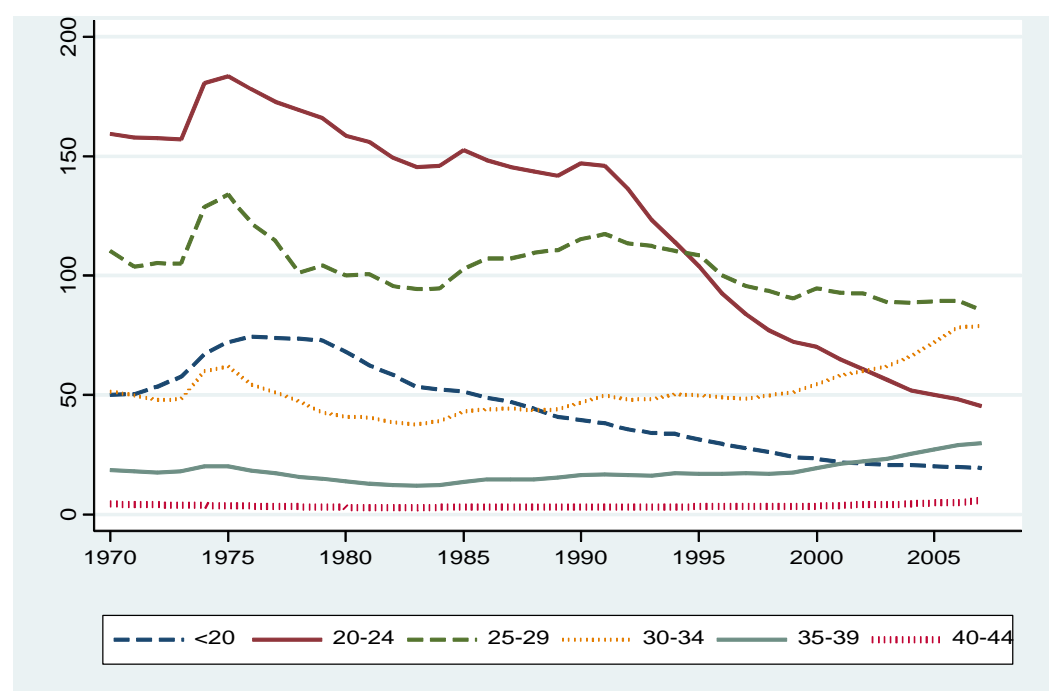

A key question is whether the fertility decline represents a permanent transition to below-replacement fertility levels or a temporary decline driven by women deciding to delay rather than forego childbearing. One approach to answering this question is to examine changes in age-specific birth rates: did younger women who postponed childbirth in the early 1990s have children a decade later? Figure 2 illustrates agespecific birth rates for Russia and Hungary from 1970 to 2007. Russia's pattern is characteristic of many countries in the Western Soviet Union, such as Ukraine and Belarus, while Hungary's pattern is typical of many East European countries. Both figures illustrate that, until the 1990s, women aged 20 to 24 had by far the highest birth rates in both countries, followed by women aged 25 to 29 . The decline in fertility rates in the 1990s was exceptionally steep for women aged 20 to 24 in both countries. In Hungary, birth rates have increased among women aged 30 to 39; if current trends continue the highest birth rates in Hungary will be for women aged 30 to 34 . This is a fundamental change in the age structure of fertility, becoming much like the West 
European pattern where the majority of childbearing is postponed until the early thirties. Later childbearing is also occurring in Russia, but women aged 20-24 continue to have the highest birth rates. The increase in birth rates among older women indicates that some of the fertility decline in formerly socialist countries was due to the postponement of births. But in the absence of other changes this increase in births is unlikely to compensate for the decline in births during the 1990s. At least for the cohort of women in their prime childbearing years during early transition, completed fertility will likely be below that of earlier cohorts.

Figure 3a: Age at first birth, former Soviet Union, 1970-2007

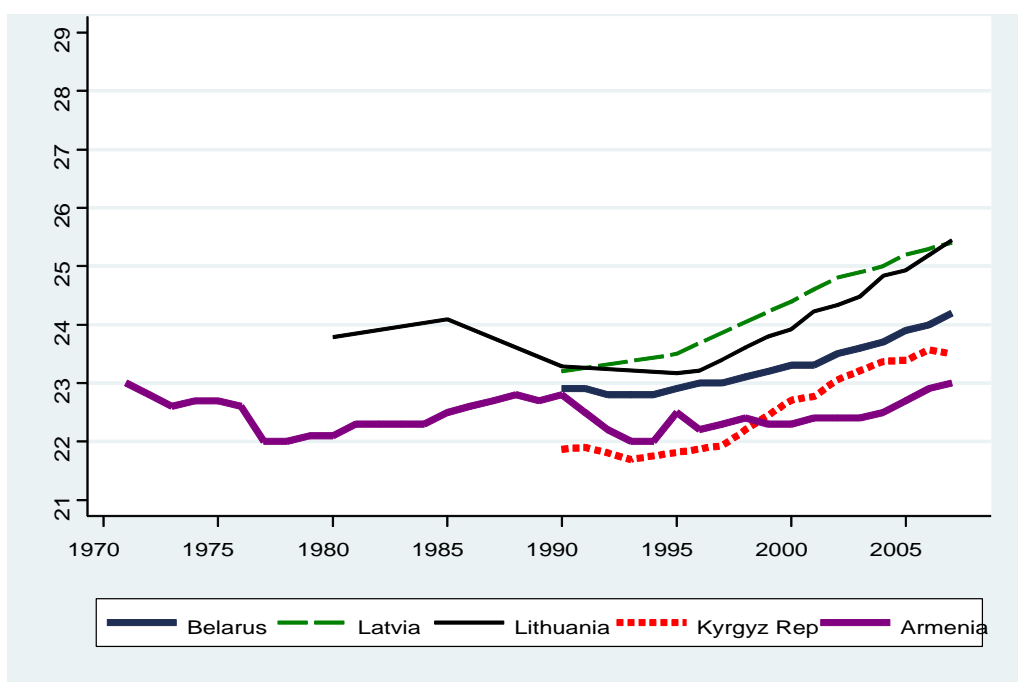

Figure 3b: Age at first birth, Eastern Europe and France, 1970-2007

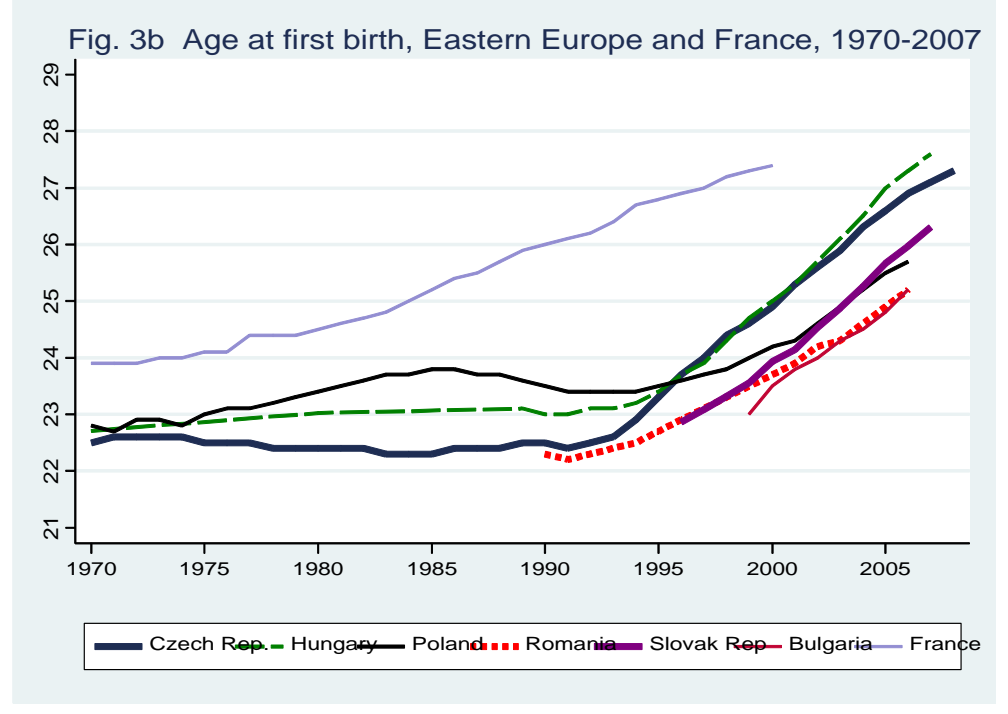

The decline in birth rates for younger women is reflected in a sharply increasing age at first birth in many countries (Figures 3a, 3b). The increase in age at first birth has been large and rapid across EE and appears to have converged with West European levels (age at first birth is shown for France in Figure 3b). Age at first birth has also increased in the FSU, although the increase has not been as steep or dramatic as in EE. Age at first marriage shows a similar pattern and appears to be approaching that of Western Europe. 
While the increase in age at first birth has occurred more slowly in Belarus, it is a clear trend, suggesting that the long-established pattern of early childbirth and marriage in the more slowly reforming countries of the FSU is beginning to change.

A further sign of demographic 'convergence' with Western Europe is the rapid increase in out-of-wedlock births experienced in most countries. As shown in Figure 4, the share of extramarital births increased across the region beginning in the early-to-mid 1990s; the highest rate is in Estonia (nearly 60 per cent of all births) which rivals the out-ofwedlock birth rates of Scandinavian countries. The contribution of extra-marital births to changes in overall fertility varies across countries. In most countries a decline in marital births accounted for the large drop in overall fertility rates in the early 1990s; in some countries, like the Czech Republic and Estonia, the increase in out-of-wedlock births has more than compensated for the decline in marital fertility and is the main reason for the slight increase in fertility rates since 2000 .

Figure 4: Percentage of births out of wedlock, 1970-2007

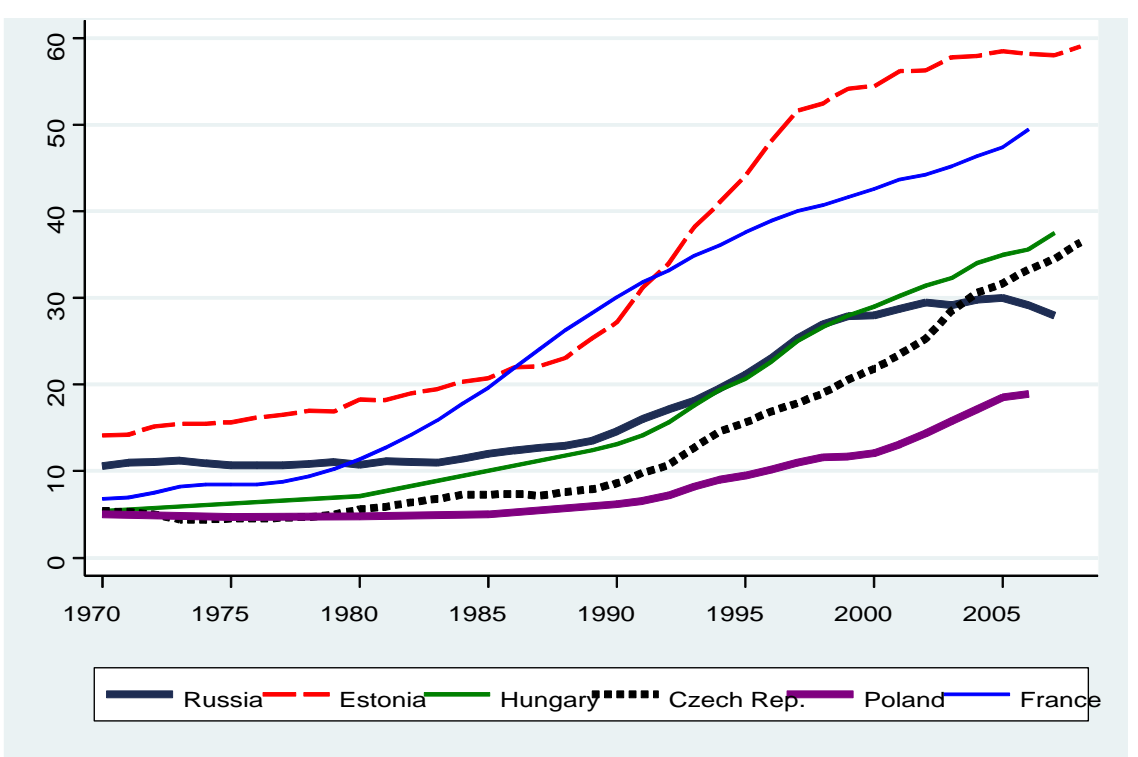

Figure 5 illustrates that the decline in birth rates was not achieved through increasing abortion rates. On the contrary, the very high abortion rate in Russia plummeted from over 100 abortions per 1,000 women aged 15-49 in 1990 to 50 by the year 2000. While abortion rates remain high compared with Western countries, the decline is significant and appears to be due at least in part to the increased availability of modern contraceptive methods in the 1990s and a resulting substitution of contraception for abortion. 4 Survey evidence also suggests that the financial cost of abortion has increased in many countries (Agadjanian 2002), which is a further reason for the decline in the abortion rate.

\footnotetext{
${ }^{4}$ See Westoff (2005) for a survey of trends in abortion and contraceptive prevalence in some of the former socialist countries. The decline of abortion in Poland is due to stringent restrictions imposed on abortion in that country in the early 1990s. See Levine and Staiger (2004) for an overview of the legislative changes to abortion laws in transition countries in the 1990s.
} 
Figure 5: Abortions per 100 births, 1989 and 2005

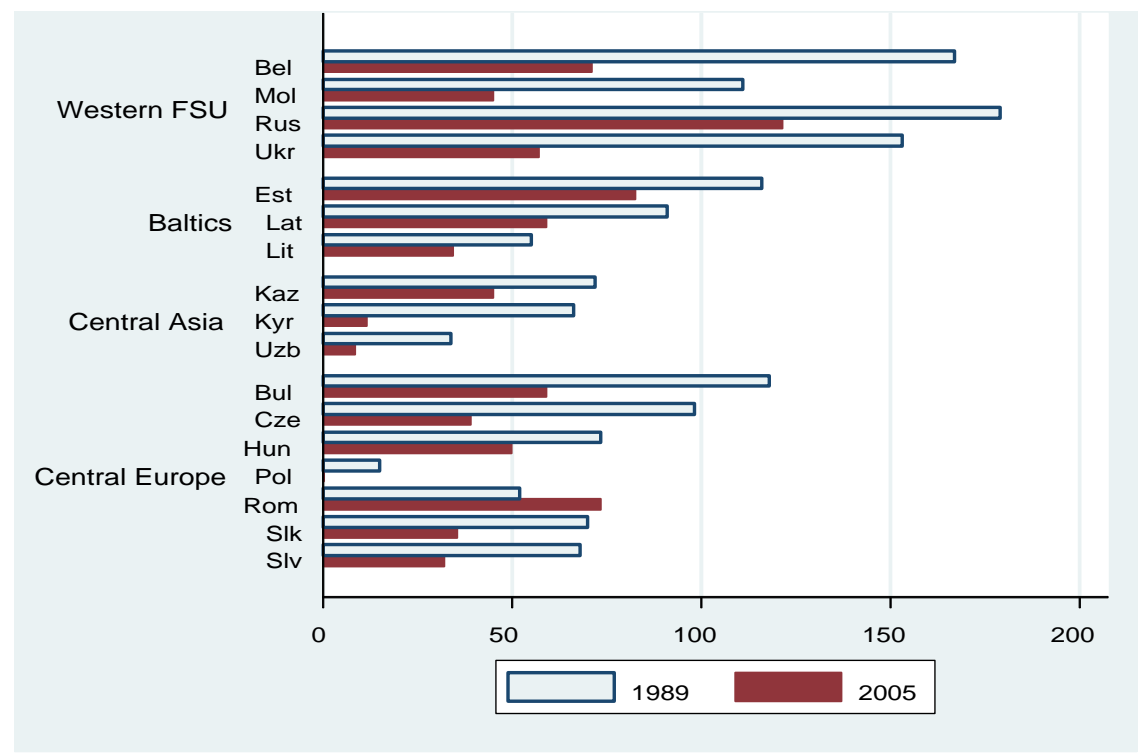

Most of the changes in the patterns of fertility and family formation described above represent a potential improvement in the welfare of children in formerly socialist countries. Later marriage and childbearing may result in parents who are better prepared, financially and otherwise, to raise a family; the increase in the use of modern contraception leads to better timing of childbirth and possibly fewer 'unwanted' children. The increase in out-of-wedlock births may be a negative trend, but even this may not be highly detrimental if the increase in extra-marital births reflects a shift from registered marriage to cohabitation rather than an increase in single parenthood. This appears to be the case in Russia (see Heleniak 2005) and is likely true in other countries as well.

But there is one fertility trend in the region that is unambiguously negative-an increase in sex ratios at birth in the Caucasus. The sex ratio in the Soviet Union had always fluctuated around the biological norm of 1.05 males to females; normal sex ratios also characterized the more traditional, less industrialized Soviet republics in Cental Asia and the Caucasus. But since the dissolution of the Soviet Union there has been a striking upward trend in the sex ratio of children aged 0 to 4 in all three Caucasian republics. Azeri official statistics indicate a sex ratio of 1.168 in 2008; the 2001 Armenian census reveals a sex ratio of 1.145; and the 2002 Georgian census shows a sex ratio of 1.104. In contrast, the sex ratio in Russia in the 2001 census is 1.049. According to these figures, excess female mortality in Armenia, Azerbaijan and Georgia appears to be at a level similar to that of China and India, where the most recent sex ratios for children aged 0-4 are 1.145 and 1.106 , respectively.

Given the Soviet state's longstanding efforts to promote the secularization of the less developed republics and equal treatment of women, including compulsory education for both boys and girls beginning in the 1930s, that such strong evidence of son preference has emerged so rapidly is surprising and difficult to explain. It is even more perplexing given the diverse cultures and religions of the three Caucasus countries. Most Armenians and Georgians are Christians (but belonging to two distinct Orthodox Churches), while Azerbaijan is a predominantly Muslim country. One should also note 
that no indication of son preference has emerged in Central Asia, despite evidence that son preference characterized all of the Central Asian countries in the twentieth century (Brainerd 2009). Demographers have concluded that the trends are real and not an artefact of inconsistencies in birth registration (Meslé et al. 2007).

\subsection{Explaining fertility change in post-socialist countries}

The standard neoclassical theory of fertility was developed by Gary Becker and is described in his influential work A Treatise on the Family (1981). One of the key insights from this work is that income and fertility may be negatively related-while children are considered to be a 'normal' good (when income increases couples desire more children), the time-intensive nature of child rearing also represents a significant opportunity cost for parents, particularly women. As women's wages have risen over the last century, the opportunity cost of having children has increased, leading to declines in fertility rates and a negative relationship between income and fertility rates. Women's relative wages have increased in many East European countries (Brainerd 2000; Grajek 2003; Joliffe and Campos 2005); this increased opportunity cost of children is likely a factor in explaining the fertility decline in the region. 5 Women have fared less well in Ukraine and Russia, however, so the increase in female wages does not provide a universal explanation for the trend across countries. A related explanation is the increase in the return to education which has occurred across nearly all transition countries, in turn inducing large increases in tertiary enrollment rates. ${ }^{6}$ As in the USA, women in many formerly socialist countries now enroll in tertiary education at a higher rate than men. In Hungary, for example, 24 per cent of women aged 25-29 have higher education, compared with only 16 per cent of men of the same age; this difference in the higher education gap has increased markedly since 1990 (see Figure 6). This increase in higher education for women further delays marriage and childbearing among younger generations. Despite problematic econometric issues, a recent study indicates that there is a causal relationship between education and fertility; an additional year of female education appears to reduce early fertility by 0.26 births (Osili and Long 2008).

Figure 7 illustrates the cross-country relationship between changes in the return to education and changes in fertility between 1990 and 2002. While a crude test of the theory, the relationship is negative and suggests that strong incentives to gain higher education have played a role in the fertility decline in EE and the FSU. Two countrylevel studies of fertility change also provide evidence of a negative relationship between fertility and education in the region. Perelli-Harris (2005), using data from the Ukrainian Reproductive Health Survey, finds that higher levels of education are significantly associated with later ages at first birth. Klasen and Launov (2006) use data from the Fertility and Family Survey of 1998 in the Czech Republic to compare the timing of births by cohort to infer the effects of education on fertility decisions under socialism versus transition. The results indicate a negative relationship between education levels and the timing of the first birth, and that the strength of this education

\footnotetext{
${ }^{5}$ While women's real wages have declined in many countries, the increase in female wages relative to male wages represents an increasing opportunity cost of fertility within the household and will still lead to the prediction of reduced fertility.

${ }^{6}$ See Flabbi et al. (2008) and Fleisher et al. (2005) for surveys of returns to education before and after transition. Campos and Joliffe (2007) find that returns to higher education increased significantly in Hungary between 1986 and 2004, and the gains were larger for women than for men.
} 
effect has increased significantly since the start of transition. Women with more education are also more likely to be childless than women with less education.

Figure 6: Share of men and women aged 25-29 with higher education, Hungary

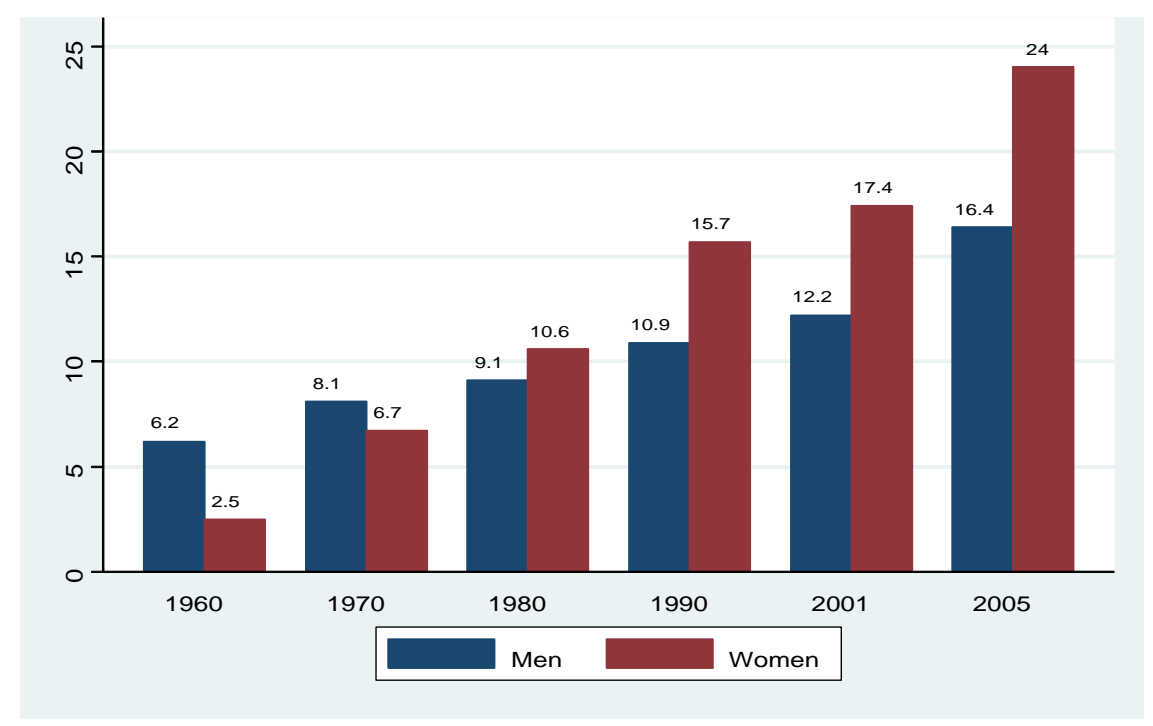

Figure 7: Changes in fertility and returns to education, 1990-2002

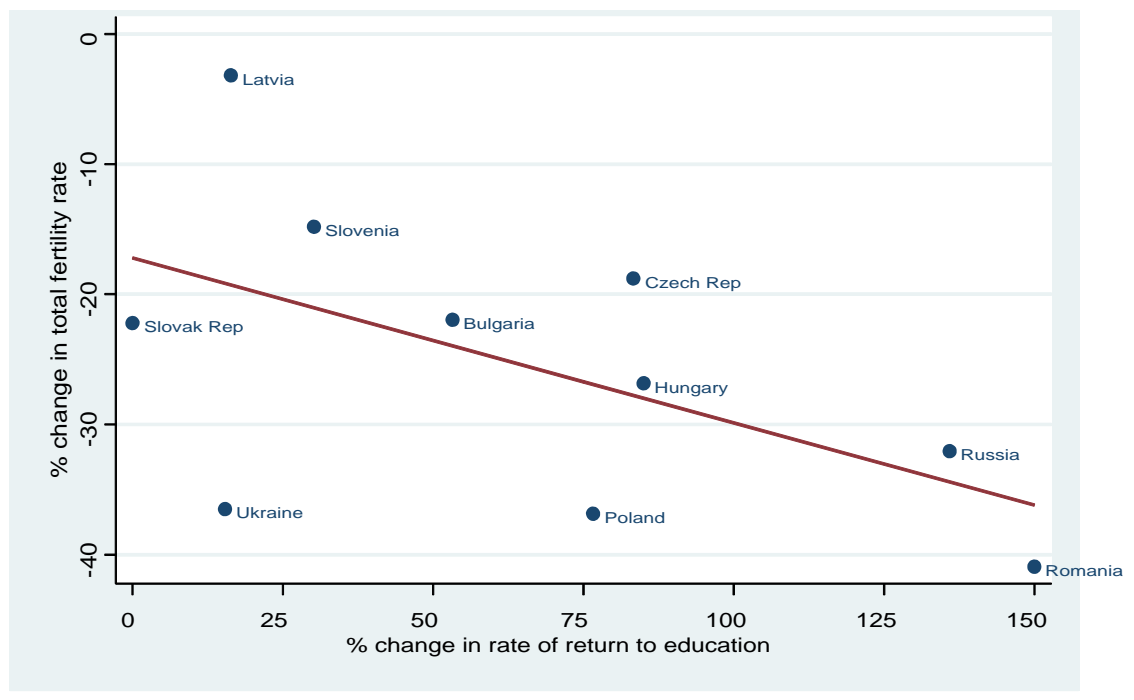

This traditional neoclassical view of fertility does not explicitly include a role for economic uncertainty in fertility decisions, which is sensible if one is trying to explain long-term changes in fertility rates. In the context of the transition countries, however, it is likely that the uncertainty surrounding the change from a socialist system to capitalism influenced couples' decisions to have children. As is well-known, workers in the socialist countries did not enjoy a high standard of living, but were entitled to stable employment and income, guaranteed pensions, universal medical care and free education. With the transition to a market economy, this social contract was broken and workers had few guarantees, facing uncertainty at the individual level regarding how well they would survive the shift and at the national level regarding the growth or stagnation of the economy under such a transition. The economic theory of investment under uncertainty has clear predictions about the optimal course of action in an 
uncertain climate; for investments which are irreversible (e.g., children) and which can be postponed, there is an option value to waiting to make the investment (Dixit and Pindyck 1994; Grogan 2006).

Several papers examining the fertility declines in the FSU and EE have focused on the role of economic uncertainty in this decline. Bhaumik and Nugent (2005) study the large fertility decline in eastern Germany between 1992 and 2002 and find a significant effect of unemployment uncertainty-particularly women's unemployment uncertainty - on the probability of childbirth. Chase (2003) examines fertility in the Czech and Slovak Republics, comparing fertility in the two countries and in the pretransition (1981-84) and post-transition (1989-93) periods. While he finds no evidence of a relationship between economic uncertainty and fertility behavior for these samples, the measure of economic uncertainty used in the paper-whether the respondent changed jobs in the past four years - is a tenuous measure of job insecurity, given that some of the respondents undoubtedly changed jobs voluntarily. Kohler and Kohler (2002) use the Russian Longitudinal Monitoring Survey to assess birth outcomes in the early period of reform, 1994-96, and find few relationships in the data between the decision to have a child and measures of labor market uncertainty. Overall, the econometric evidence on the effect of uncertainty on fertility behavior is mixed.

A number of other factors may have accelerated the decline in fertility in EE and the FSU during the 1990s. One of these is the decrease in the number of state-supported nurseries and pre-school facilities and the near-disappearance of daycare facilities provided at enterprises. For example, in Russia the share of children in kindergarten and nurseries declined by over 55 per cent between 1989 and 1997; the price of such care also rose sharply in this period (Lokshin 2005). An additional factor is simply the decrease in the number of middle-aged men; as described below, many former Soviet countries experienced a dramatic increase in mortality rates among men aged 25-54 in the 1990s. If women are reluctant to raise a child as a single mother, this too would be expected to account for at least part of the decline in fertility over the period.

To summarize, the formerly socialist countries have experienced a remarkably rapid change in fertility and family formation in the two decades since 1989. On many dimensions the region now looks like Western Europe, with low fertility rates, later marriage and childbearing, and high and rising out-of-wedlock birth rates. Some of the changes appear to be driven by changes in returns to education and economic uncertainty, but to date there is a paucity of research seeking to explain these fundamental shifts in behavior.

\section{Mortality}

Between 1990 and 1994 the death rate among working age men in Russia increased by 70 per cent, from 759.2 to 1323.7 deaths per 100,000 population. Male life expectancy at birth fell from 63.7 years to 57.4 years during that period, while female life expectancy at birth fell from 74.3 years to 71.1 years. A similar increase in mortality rates occurred in many other countries of the FSU in the early 1990s, in particular in Belarus, Ukraine, and the three Baltic countries. Although some of the declines in life expectancy were reversed in Russia and many of its neighbors in the late 1990s, the magnitude of the declines and the large and erratic swings of this usually slowly- 
evolving indicator are unprecedented in the twentieth century for countries at peace and in the absence of major famines or epidemics.

The timing of this demographic crisis coincided with the introduction of market reforms in the FSU, suggesting that rising mortality was related to the transition to a market economy. But mortality trends in the transition countries of EE differ markedly from those of the FSU; despite declining GDP and sharply rising unemployment rates in many East European countries in the early-to-mid 1990s, mortality rates fell and life expectancy rose throughout the region. The unprecedented increase in cardiovascular mortality in the FSU in the early 1990s was nearly matched by an unprecedented decrease in cardiovascular mortality in EE. Why did mortality trends differ so markedly between the two regions? This section explores some of the possible explanations; as will become evident, a clear answer to the question remains elusive.

\subsection{Trends in life expectancy and age- and cause-specific mortality}

The change in male life expectancy at birth is shown in Figure 8 for selected countries. ${ }^{7}$ This figure illustrates the differing mortality experiences of the FSU and EE. In the FSU changes in life expectancy are erratic and appear to be sensitive to macroeconomic fluctuations; in EE every country has experienced a sustained increase in life expectancy since the early-to-mid 1990s.8 Despite the recent improvements in life expectancy in the FSU since the mid 1990s, male life expectancy remains extremely low, both historically and in comparison with other developed countries. In Russia, for example, male life expectancy at birth in 2007 was 61.39 years; this represents a decline of 1.60 years from the level of male life expectancy in Russia in 1958, and a difference of over 16 years with male life expectancy in France (77.6 years in 2007). In 1958, male life expectancy in France exceeded that of Russia by only 3.81 years. East European countries are, in contrast, slowly closing the life expectancy gap with Western Europe; the difference in male life expectancy between France and the Czech Republic in 1989 was 4.38 years, falling to 3.93 years by 2007 .

The mortality crisis in the FSU primarily affected middle-aged men. The groups traditionally most vulnerable to the health effects of economic crisis-children and the elderly-avoided large increases in mortality during transition. In fact, infant and child mortality declined in almost all countries across the region during the 1990s.

Changes in death rates by five-year age groups for Russia, Estonia, and Hungary are shown in Figure 9. In Estonia and Russia (and many other former Soviet countries), the increase in death rates for men aged 25-54 between 1989 and 1994 was astonishing. In Estonia, for example, the death rate for men aged 40-44 increased from 5.93 deaths per 1,000 men in this age group in 1989 to 13.19 deaths per 1,000 in 1994, an increase of

\footnotetext{
${ }^{7}$ Life expectancy trends for women are similar in all countries to those of men, although the decline in life expectancy in the former Soviet Union is less dramatic for women than for men. For studies of mortality in individual countries, see Badurashvili et al. (2001) on Georgia; Shkolnikov et al. (2001) on Russia; Dolea et al. (2002) on Romania; and Becker and Urzhumova (2005) on Kazakhstan.

8 The quality of mortality statistics in the formerly socialist countries is considered to be reasonably reliable. A few exceptions include the likely underestimation of infant mortality rates in the Caucasus and Central Asia (Aleshina and Redmond 2005); questionable adult mortality data for Armenia and Georgia (Badurashvili et al. 2001; Stillman 2006) and possible over-reporting of deaths due to ill-defined conditions’ and underreporting of deaths due to external causes in Russia (Gavrilova et al. 2008).
} 
122 per cent. Over the entire transition period (right panel of Figure 9), the increase in death rates among middle-aged men remained high in Russia, but had begun to decline in Estonia and the other Baltic republics.

Even in some East European countries the death rate among middle-aged men increased during the early years of transition. This increase was most prominent in Hungary, where the age-specific death rate for men aged 40-44 increased from 6.82 per 1,000 population in 1989 to 9.08 in 1994, and in Romania, where the death rate increased by over 43 per cent for these men between 1990-97. However, by 2007 all age groups experienced significant declines in mortality rates in Hungary, with the largest declines among younger men (right panel of Figure 9). This pattern of large declines in mortality rates across most age groups by 2007 is similar for all East European countries for which data are available, including the Czech Republic, Poland and Romania.

Figure 8: Male life expectancy at birth in formerly socialist countries
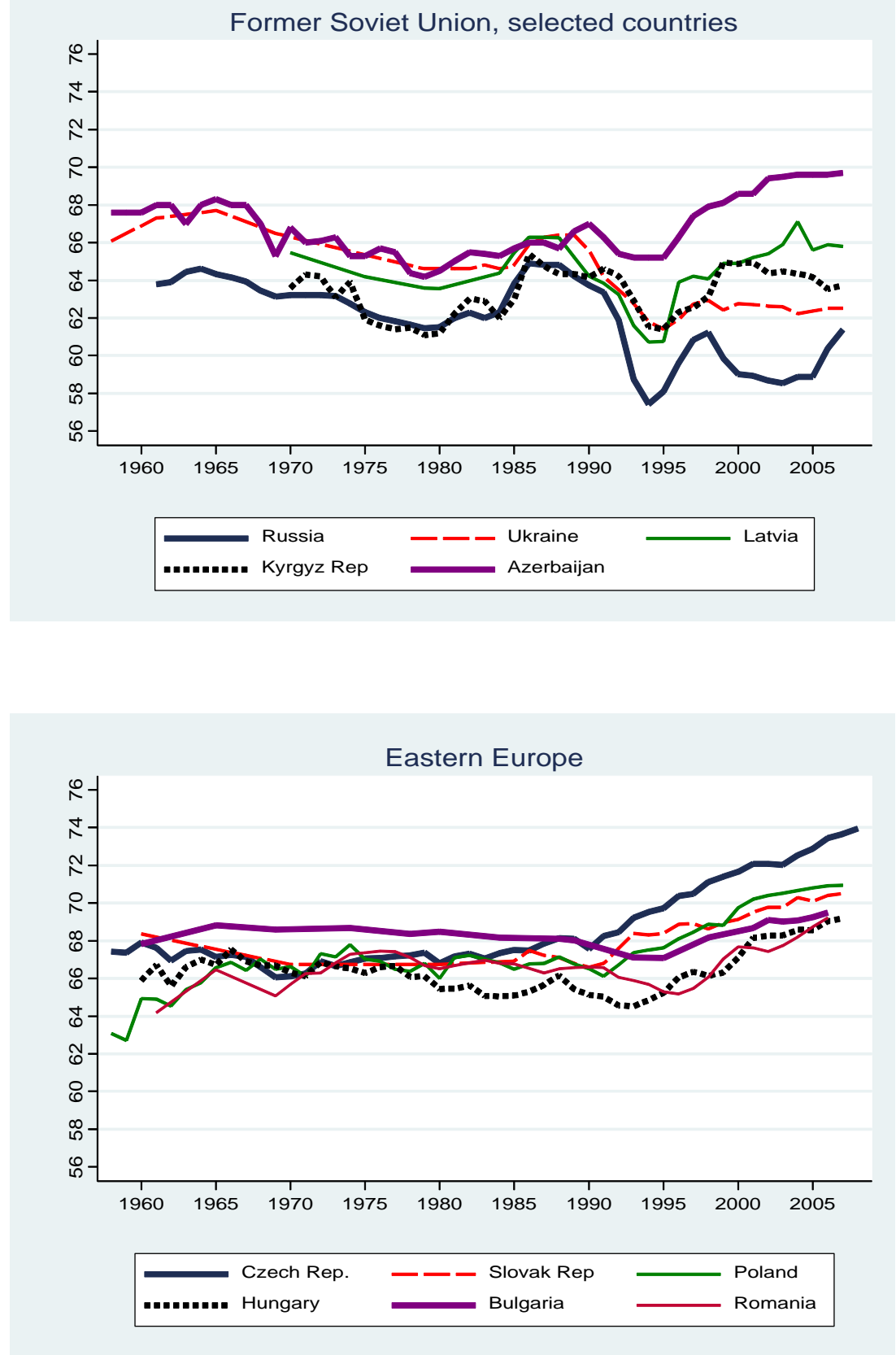
Figure 9: Percentage change in death rate by age group, men
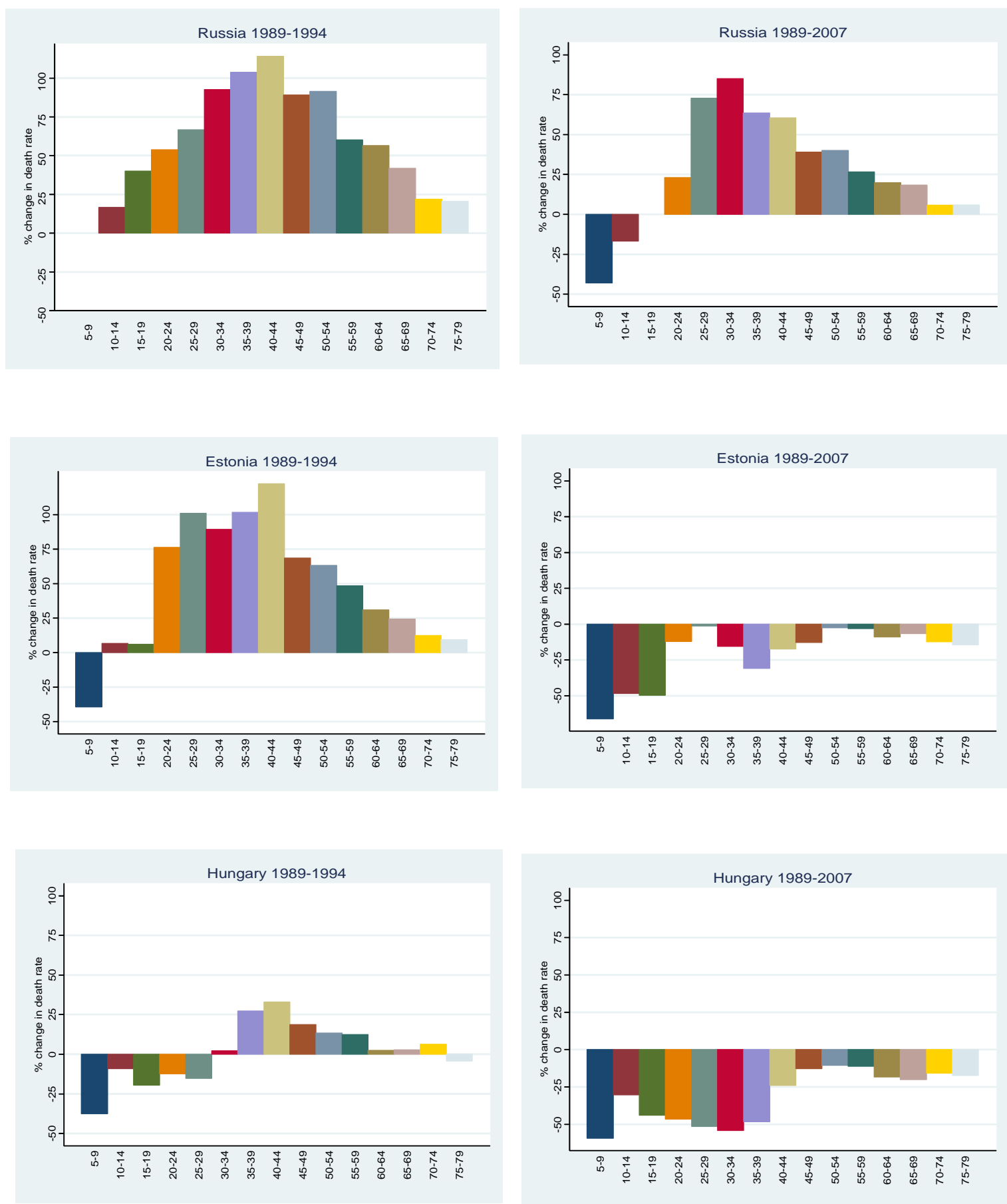

The increase in death rates in the FSU in the early 1990s was primarily due to a tremendous increase in deaths due to circulatory diseases (heart disease and strokes) and due to external causes. Changes in the age-standardized death rate for men aged 25-64 due to circulatory diseases are shown in Figure 10. In the FSU, the death rate from both of these broad categories of death was much higher than in other developed countries even prior to the transition. All former USSR countries experienced a significant increase in circulatory disease and external cause deaths between 1989 and 1994. The external cause deaths include an epidemic of homicide and suicide across the region, 
peaking around 1994 and again primarily affecting working age men. For example, in Lithuania the death rate due to suicide among men aged 45-54 increased from 109 deaths per 100,000 population in 1985-already extremely high compared with Western countries-to 160 deaths per 100,000 population in 1995. After the mid 1990s these death rates declined but remain at least as high as in the pre-transition period in most countries. The Russian mortality pattern differs somewhat from that of other former Soviet countries, as cardiovascular disease and external cause deaths spiked up again following the 1998 financial crisis until finally beginning to decline in 2005.

Figure 10: Standardized death rate, circulatory diseases, men aged 25-64
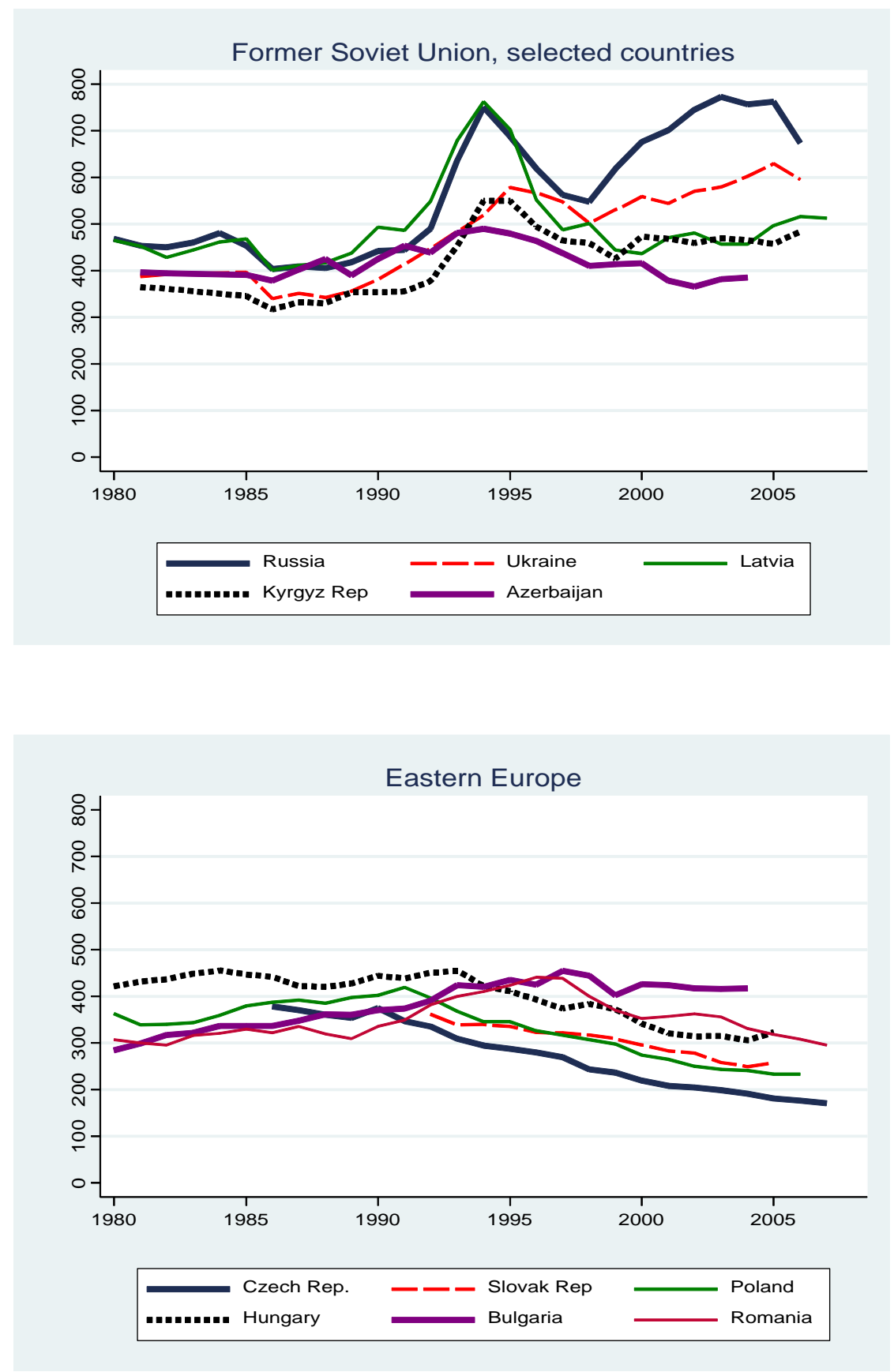

Source: WHO Mortality Database (January 2009 version). 
The pre-transition rates of circulatory diseases were also significantly higher in EE than in Western Europe across the region, and increased by 17 per cent and 33 per cent, respectively, among men aged 25-64 in Bulgaria and Romania between 1989 and 1994. In the other EE countries, deaths due to circulatory diseases for men in this age group declined substantially between 1989 and 2007. In the Czech Republic, for example, deaths due to cardiovascular disease fell from 354 to 170 deaths per 100,000 population between 1989-2007 for men aged 25-64. While nearly all developed countries have recorded significant declines in circulatory disease mortality in recent decades, the speed and magnitude of the decline in EE may be unprecedented. Deaths due to external causes were always much lower in EE than in the FSU (although about twice as high as in Western Europe), and these causes of death have changed relatively little during the transition period. 9 The one cause of death with negative trends in some East European countries is deaths due to chronic liver disease and cirrhosis which have increased significantly in Hungary, Romania and Moldova; this trend, along with a small increase in deaths due to cardiovascular disease, likely accounts for the increase in deaths among men aged 40-44 noted above.

\subsection{Did Russians drink themselves to death?}

Deaths due to chronic liver disease and cirrhosis also increased in Russia and the Baltics in the 1990s, but the death rates from these diseases are far too low to account for the increase in mortality in the region. 10 Nevertheless, most analysts believe that alcohol consumption is one of the major causes of the large swings in mortality in western FSU in the 1990s. Brainerd and Cutler (2005) analyze the cross-country differences in mortality in EE and the FSU, and identify alcohol consumption, stress, and possibly diet, as contributing factors. This study, like many others in this area of research, concludes that a significant share of the change in mortality in the FSU remains unexplained.11 Limited data combined with the widespread nature of the crisis across regions, cohorts and types of death has frustrated efforts to identify the causes of the mortality crisis and this in turn has hampered the efforts of governments, health care providers, and international donors to identify and implement policies to reduce premature adult mortality.

One puzzle in attempting to explain the swings in cardiovascular mortality in the FSU is that the prevalence of the principal risk factors for cardiovascular disease (CVD) smoking, hypertension, and high cholesterol levels-in former Soviet countries is somewhat lower than in the Western countries that have much lower rates of cardiovascular disease, and that trends in these risk factors were mildly favorable over the 1990s (Puska et al. 1993; Kristenson et al. 1997; Stegmayr et al. 2000; Averina et al. 2003). On this basis most researchers have concluded that conventional CVD risk

\footnotetext{
${ }^{9}$ One exception to the statement in Hungary, where suicide rates have declined from high levels in the pre-transition period to much lower rates in recent years; the suicide rate for men aged 45-49 fell from 104 deaths per 100,000 population in 1989 to 73 deaths per 100,000 population in 2007.

${ }^{10}$ For example, in Russia the male death rate from cirrhosis increased from 14.2 to 27.1 deaths per 100,000 population between 1989 and 1994, while the overall male death rate increased from 1,629.5 to 2,290.5 deaths per 100,000 population over the same period.

${ }^{11}$ Chen et al. (1996) gives an insightful summary of hypotheses and evidence on the causes of Russia's mortality crisis. Edited collections of papers on mortality in transition include Bobadilla et al. (1997); Becker and Bloom (1998); Cornia and Paniccià (2000). Stillman (2006) provides a comprehensive survey of the literature on health and mortality in transition countries.
} 
factors fail to explain the high levels and large increases in cardiovascular mortality in the FSU. Some argue instead that non-traditional risk factors account for high CVD mortality in this region, in particular that the style of drinking (binge drinking) negates the protective effect of alcohol on the heart and leads to increased arrhythmias and heart attacks (McKee and Britton 1998). Recent research provides supportive evidence of this idea; for example a small case-control study of adult male deaths in Udmurtia (the Urals) confirmed that cardiovascular deaths are strongly associated with periods of heavy drinking among adult men (Shkolnikov et al. 2001). Another study of 25-64 year old men in Novosibirsk (Siberia) found an increased risk of CVD and external cause mortality among frequent heavy drinkers (Malyutina et al. 2002).

Evidence also suggests that the high number of deaths in Russia classified as due to 'other' or 'unspecified' ischemic heart disease may be overstated and that these deaths are more properly classified as deaths from alcohol poisoning. An analysis of nearly 25,000 autopsies conducted in Barnaul (Siberia) between 1990-2004 indicated that 21 per cent of all autopsied adult male deaths attributed to circulatory diseases had lethal or near-lethal levels of ethanol concentration in the blood (Zaridze et al. 2009a). A further study of 48,000 deaths in three Siberian cities led the authors to conclude that alcohol consumption may be responsible for more than half of all adult male deaths in Russia from 1990 to 2001, and one-third of adult female deaths (Zaridze et al. 2009b).

Recent research has also highlighted the important role the consumption of 'surrogate' alcohol has played in the mortality crisis in Russia. A significant amount of alcohol is consumed in the form of either homemade alcohol (samogon), which has high ethanol concentrations, or 'non-beverage' alcohol, such as after-shave, anti-freeze and lighter fluid which contain high concentrations of ethanol and toxic ingredients (McKee et al. 2005; Leon et al. 2007). These forms of alcohol are untaxed and, per liter of pure alcohol, are much cheaper than vodka sold in retail stores. The combination of high ethanol concentrations and toxic ingredients also makes these surrogate alcohol products much more lethal than commercially sold vodka.

The autopsy studies and surrogate alcohol studies provide persuasive evidence that alcohol consumption played an even more important role than previously thought in the increase in deaths due to both cardiovascular and external causes in Russia. But there are still many unanswered questions regarding the role of alcohol consumption in the mortality crisis. First, does alcohol consumption also explain the large swings in mortality in the other countries of the FSU besides Russia? Evidence on other countries is much more limited since most of the epidemiological research has focused on the mortality crisis in Russia. A study by Chenet et al. (2001) shows that the pattern of alcohol consumption and CVD mortality in Lithuania is similar to that of Russia; another study indicates that binge drinking of grain-based alcohol is characteristic of Ukraine and the Baltics but not of EE (Popova et al. 2007). This evidence suggests that alcohol consumption explains much of the increase in mortality across the FSU in the early 1990s but is far from conclusive; additional research is needed on the mortality experiences of other countries to establish this conclusion. A second question is: why did drinking become so lethal in the 1990s? Did alcohol consumption increase a great deal, or the frequency of binge drinking? Given the difficulty of measuring alcohol intake at either the national or individual levels this question may be impossible to answer. It is clear that the price of alcohol relative to the price of food fell dramatically 
in the early years of transition in Russia which likely exacerbated the tendency to consume alcohol.12

A key piece of information needed to better understand the effects of such price changes on alcohol consumption is the price (and income) elasticity of demand for alcohol in former Soviet countries, as well as the cross-price elasticity of demand between storebought vodka and surrogate alcohol consumption. One approach to the drinking problem is to raise taxes on alcohol; studies of the US population, for example, indicate that higher alcohol prices reduce binge drinking among youth.13 But it is quite possible that higher alcohol prices would worsen mortality in the FSU; higher prices for alcohol sold through official outlets may induce individuals to substitute low-quality surrogate alcohol and homemade alcohol for higher-quality alcohol, which in turn could lead to increased deaths from accidental alcohol poisoning. To date, however, studies of the price and cross-price elasticity of demand for alcohol in the FSU have not been conducted.

Turning to Eastern Europe, researchers have devoted even less attention to explaining changes in mortality rates in this region. It is clearly of interest, however, to understand why the mortality outcomes in this region have been so different from that of the FSU, especially given that the improvement in cardiovascular mortality in some of these countries has been so remarkable and unexpected.

The few studies that have examined mortality trends in EE have identified changing diet as the most likely explanation for the rapid improvement in CVD mortality rates. The end of state subsidies for meat and the greatly increased availability of fruits and vegetables led to a radical change in the diet of much of the population in the region in the early 1990s. Foremost among the changes was a shift in the consumption of animal fat to vegetable fat, and an increase in the intake of antioxidants. This dietary shift occurred in the Czech Republic (Dzúrová 2000) and in Poland (Zatonski 1998). Bobak et al. (1997) document a decrease in cholesterol levels among Czech men and women after 1988 which they attribute to the increase in consumption of vegetable fats. As an example, per capita consumption of butter in the Czech Republic fell from $9.4 \mathrm{~kg}$ in 1989 to $5.4 \mathrm{~kg}$ in 1992. Zatonski et al. (2008) further argue that a shift from the use of sunflower oil to rapeseed oil in many East European countries contributed to the decline in CVD mortality in EE; rapeseed oil is relatively high in fatty acids which are beneficial to cardiovascular health, while sunflower oil lacks these fatty acids. Researchers argue that the health effects of dietary change can occur relatively quickly, appearing within two to three years from the change in diet (Zatonski et al. 1998).

A secondary reason for the reduction in mortality rates in East European may be improved quality of medical care. Evidence on this factor is very sparse, however. The study by Dzúrová (2000) identified improvements in the supply of cardiovascular medicines and medical equipment and an increase in cardiovascular operations as major reasons for improved cardiovascular mortality in the Czech Republic. And it is likely that the substantial reductions in infant and child mortality are attributable to improvements in medical care. Given the lack of evidence, however, the contribution of improved medical care to increasing life expectancy in EE remains speculative.

\footnotetext{
${ }^{12}$ Treisman (2008) analyzes the effects of the decline in the price of vodka on mortality in Russia.

${ }^{13}$ See Cook and Moore (2000) for reviews of this literature.
} 


\section{Consequences of demographic change in Eastern Europe and the former Soviet Union}

Declining fertility and rising mortality have combined to produce significant decreases in population size across most countries of the FSU in the last two decades. In Russia, the population stood at 147 million in 1989 but had fallen to 142 million by 2008, a loss of 3.4 per cent. The population decline is even more dramatic if one excludes the substantial net immigration inflows that Russia experienced over the period; over 6 million (net) immigrants arrived between 1989-2008, indicating that the number of native Russians fell by 11 million in those years. As shown in Figure 11, the population loss in Russia was small compared with other countries of the western part of the FSU: the population fell by nearly 20 per cent in Moldova and Georgia, by nearly 15 per cent in Estonia and Latvia, and by 4-10 per cent in Kazakhstan, Armenia, Lithuania and Ukraine. Bulgaria and Romania experienced similar population declines. The only countries with growing populations over the period were the Central Asian countries (besides Kazakhstan), Azerbaijan and Hungary.

Figure 11: Population change 1989-2008

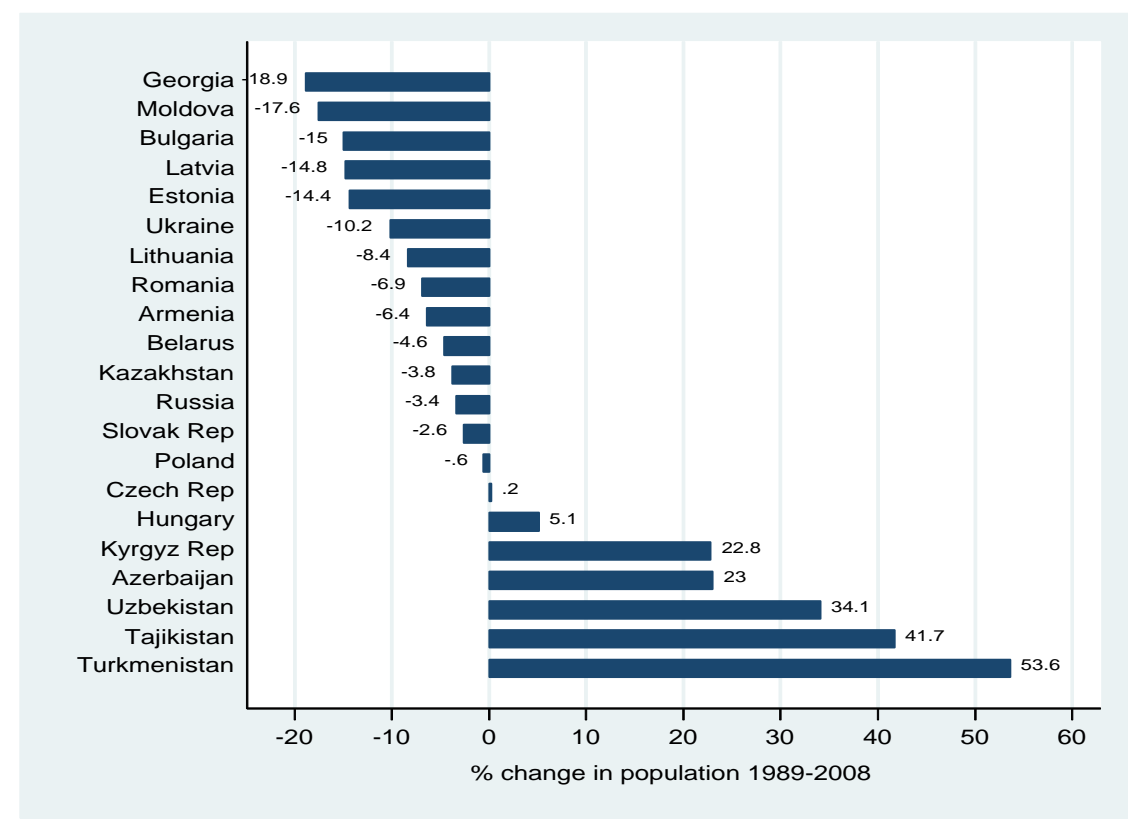

Source: TransMONEE database (2009 version).

What are the economic consequences of population declines of this magnitude? Few countries have experienced a sustained decrease in population size like that recorded in the western FSU, so there is scant historical evidence on which to rely to make predictions. One should also recognize that population declines are likely to continue in many countries due to the much smaller cohorts of women entering their childbearing years. In Russia there were 12 million women aged 20-29 in 2008; this number will fall to only 7 million by 2020 (Heleniak 2005). Even if Putin's fertility 'bonus' spurs an increase in fertility in Russia, mechanically it is nearly impossible for such an increase to compensate for the small cohort of women of childbearing age. Recognizing this, the Russian statistical agency forecasts the population to decrease from 142 million in 2008 
to 137.5 million in 2025 (Federal State Statistics Service 2008). The pace of negative population growth may be mitigated in some countries by increasing life expectancy, however, and the actual outcomes will be strongly affected by the immigration policies enacted by each country.

Assuming that population declines continue in some of the formerly socialist countries, the canonical Solow growth model predicts that this decrease can be beneficial for economic growth: the smaller population leads to an increase in the capital-labor ratio, thus increasing productivity and growth. Young (2005) uses this basic insight to calibrate a growth model for South Africa, showing that the AIDS tragedy could lead to higher wages and economic growth among survivors through this mechanism. A related question is how changes in population health, as proxied by life expectancy, affect economic growth. While much of the literature on this issue has shown a positive relationship between life expectancy and economic growth across countries, the likely reverse causality between growth and health (and omitted variable bias) has hindered efforts to demonstrate that the relationship between the two is causal. Acemoglu and Johnson (2007) use an instrumental variables approach to demonstrate that the health improvements in the post-war period had an inconsequential or a slightly negative effect on growth. In a reply to that paper, Bloom et al. (2009b) show that, allowing for a lagged (rather than instantaneous) effect of health on growth, there is a positive and statistically significant relationship between life expectancy and economic growth across countries. Given that even the sign of the relationship between life expectancy and growth remains in dispute, it is difficult to predict how changing life expectancy in $\mathrm{EE}$ and the FSU will affect long-term economic growth. If the relationship is positive (and causal), the rapid gains in life expectancy in EE will enhance the region's growth prospects.

Another route through which the demographic changes will affect growth is through the changing age structure of the population. Almost all countries in the region experienced an increase in the share of the population older than working age in the last twenty years. In Bulgaria, for example, the elderly dependency ratio14 reached 37.4 per cent in 2008, as compared with 30.9 per cent in 1989. In all three Baltic countries the elderly dependency ratio is at nearly 35 per cent. This trend is likely to continue given declining fertility and rising life expectancy in most countries. Increases in the elderly dependency ratio pose a threat to government-funded retirement programs that rely on contributions from current workers to maintain solvency. And as emphasized by Bloom et al (2009a), changing age structure of the population is a crucial mechanism through which changing fertility (and mortality) can affect economic growth. These authors argue that, while declining fertility can lead to an increase in economic growth in the short run through the standard Solow effect, in the long run the increase in the inactive share of the population will have negative effects on economic growth.

Further consequences of the mortality changes in the region will likely operate through changes in human capital. In the FSU, the steep death rates of men aged 25-54 represent a massive loss of human capital among a segment of the population in their most productive working years. To the extent that this human capital was transferable from the socialist economic system to the market economies of the region, this loss likely represents a negative shock to economic growth. The high adult mortality rates of the

\footnotetext{
${ }^{14}$ Defined as the population aged 60 and over divided by the population aged 15-59 years.
} 
region also shorten individuals' time horizons and will lead to lower investments in human and physical capital, further depressing the economic growth prospects of the region. 15 The opposite effect may boost the economic growth prospects of the EE countries - as adult mortality rates continue to decline, changing time horizons and improved health should induce individuals to increase their investments in human and physical capital.

\section{Concluding remarks}

Rarely in modern history has a population experienced such a fundamental transformation of life circumstances in such a short period of time as that experienced by the people of Eastern Europe and the former Soviet Union in the last two decades. Women in the region now postpone marriage and childbirth and have children out of wedlock in patterns similar to that of Western Europe. Men in EE are much less likely to die of cardiovascular disease than they were 20 years ago, while the opposite is true of men in the FSU. These trends and patterns are clear, but much remains unknown about the underlying reasons for these changes. There is a dearth of convincing research explaining the decline in fertility and marriage in formerly socialist countries. Few studies have examined the relationship between changing labor market opportunities for women and changing fertility behavior in the region. And little is known about the causes and consequences of the decline in abortion as a mode of contraception in the FSU, or of the impact of Poland's near-ban on abortion in the early 1990s.

The need for more research is perhaps even greater on the mortality side of the ledger. Without a clear understanding of the causes of the mortality crisis it is difficult to design policies to mitigate premature mortality in these countries. As discussed above there are large gaps in the current research relating to the responsiveness of alcohol consumption to price changes, and to the causes of the mortality crisis in FSU countries other than Russia. In addition, an improved understanding of the reasons for the decrease in cardiovascular mortality in EE has the potential to provide new insights into the underlying causes of cardiovascular mortality that would benefit at-risk populations in all countries. As has long been the case even before the fall of communism, the unique and puzzling demography of Eastern Europe and the former Soviet Union presents a myriad of questions for researchers to investigate.

\section{References}

Acemoglu, D., and S. Johnson (2007). 'Disease and Development: The Effect of Life Expectancy on Growth’. Journal of Political Economy, 115(6) 925-85.

Agadjanian, V. (2002). 'Is “Abortion Culture” Fading in the Former Soviet Union? Views About Abortion and Contraception in Kazakhstan'. Studies in Family Planning, 33(3): 237-48.

\footnotetext{
${ }^{15}$ Lorentzen et al. (2008) show that high adult mortality reduces economic growth across countries due to shortened time horizons and increased risky behavior.
} 
Aleshina, N., and G. Redmond (2005). 'How High is Infant Mortality in Central and Eastern Europe and the Commonwealth of Independent States?'. Population Studies 59(1): 39-54.

Averina, M., O. Nilssen, T. Brenn, J. Brox, A.G. Kalinin, and V.L. Arkhipovsky (2003). 'High Cardiovascular Mortality in Russia Cannot Be Explained by the Classical Risk Factors: The Arkhangelsk Study 2000'. European Journal of Epidemiology, 18: 87178.

Badurashvili, I., M. McKee, G. Tsuladze, F. Meslé, J. Vallin and V. Shkolnikov (2001). 'Where There Are No Data: What Has Happened to Life Expectancy in Georgia Since 1990?'. Public Health, 115: 394-400.

Barkalov, N.B. (2005). 'Changes in the Quantum of Russian Fertility During the 1980s and Early 1990s'. Population and Development Review 31(3): 545-56.

Becker, C.M., and D. Bloom (eds) (1998). 'The Demographic Crisis in the Former Soviet Union'. World Development 26(11): 1957-75.

Becker, C.M. and D.S. Urzhumova (2005). 'Mortality Recovery and Stabilization in Kazakhstan, 1995-2001’. Economics and Human Biology, 3: 97-122.

Becker, G.S. (1981). A Treatise on the Family. Harvard University Press: Cambridge, MA.

Bhaumik, S.K., and J.B. Nugent (2005). 'Does Economic Uncertainty Affect the Decision to Bear Children? Evidence from East and West Germany'. IZA Discussion Paper No. 1746.

Bloom, D.E., D. Canning, G. Fink, and J.E. Finlay (2009a). 'The Cost of Low Fertility in Europe'. NBER Working Paper No. 14820.

Bloom, D.E., D. Canning, and G. Fink (2009b). 'Disease and Development Revisited'. NBER Working Paper No. 15137.

Bobadilla, J.L., C.A. Costello, and F. Mitchell (eds) (1997). Premature Death in the New Independent States. National Academy Press: Washington DC.

Bobak, M., Z. Skodova, Z. Pisa, R. Poledne, M. Marmot (1997). 'Political changes and trends in cardiovascular risk factors in the Czech Republic, 1985-1992'. Journal of Epidemiology and Community Health, 51: 272-7.

Brainerd, E. (2000). 'Women in Transition: Changes in Gender Wage Differentials in Eastern Europe and the Former Soviet Union'. Industrial and Labor Relations Review, 54(1): 138-62.

Brainerd, E., and D.M. Cutler (2005). 'Autopsy on an Empire: Understanding Mortality in Russia and the Former Soviet Union'. The Journal of Economic Perspectives, 19(1): 107-30.

Brainerd, E., (2009) 'Missing Women in the Former Soviet Union? Son Preference and Children’s Health in Central Asia and the Caucasus During Transition’. Mimeo.

Campos, N., and D. Jolliffe (2007). 'Earnings, Schooling and Economic Reform: Econometric Evidence from Hungary (1986-2004)’. World Bank Economic Review, 21(3): 509-26. 
Chase, R.S. (2003). 'Household Fertility Responses Following Communism: Transition in the Czech Republic and Slovakia.' Journal of Population Economics 16 579-95.

Chen, L.C., F. Wittgenstein, and E. McKeon (1996). 'The Upsurge of Mortality in Russia: Causes and Policy Implications'. Population and Development Review, 22(3): 517-30.

Chenet, L., A. Britton, R. Kalediene, and J. Petrauskiene (2001). 'Daily variations in deaths in Lithuania: the possible contribution of binge drinking'. International Journal of Epidemiology, 30: 743-48.

Cook, P.J., and M.J. Moore (2000). 'Alcohol'. In A.J. Culyer and J.P. Newhouse (eds) Handbook of Health Economics. Elsevier: Amsterdam.

Cornia, G.A., and R. Paniccià (eds) (2000). The Mortality Crisis in Transitional Economies. Oxford University Press: Oxford.

Dixit, A.K., and R.S. Pindyck (1994). Investment under Uncertainty. Princeton University Press: Princeton, NJ.

Dolea, C., E. Nolte, and M. McKee (2002). 'Changing Life Expectancy in Romania after the Transition'. Journal of Epidemiology and Community Health, 56(6): 444-9.

Dzúrová, D. (2000). 'Mortality Differentials in the Czech Republic during the Post1989 Socio-Political Transformation’. Health \& Place, 6: 352-62.

Federal State Statistics Service of Russia (2008). Demographic Yearbook of Russia 2008. Federal State Statistics Service of Russia: Moscow.

Flabbi, L., S. Paternostro, and E.R. Tiongson (2008). 'Returns to Education in the Economic Transition: A Systematic Assessment Using Comparable Data'. Economics of Education Review, 27: 724-40.

Fleisher, B.M., K. Sabirianova, and X. Wang (2005). 'Returns to Skills and the Speed of Reforms: Evidence from Central and Eastern Europe, China, and Russia'. Journal of Comparative Economics, 33: 351-70.

Gavrilova, N.S., V.G. Semyonova, E. Dubrovina, G.N. Evdokushkina, A.E. Ivanova, and L.A. Gavrilov (2008). 'Russian Mortality Crisis and the Quality of Vital Statistics,' Population Research and Policy Review, 27 (5): 551-74.

Grajek, M., 'Gender Pay Gap in Poland’. Economics of Planning, 36(1): 23-44.

Grogan, L. (2006). 'An Economic Examination of the Post-Transition Fertility Decline in Russia’. Post-Communist Economies, 18(4): 363-97.

Heleniak, T. (2005). 'The Causes and Consequences of Fertility Decline in the Former Soviet Union and Central and Eastern Europe’. Mimeo.

Jolliffe, D., and N.F. Campos (2005). 'Does Market Liberalisation Reduce Gender Discrimination? Econometric Evidence from Hungary, 1986-1998'. Labour Economics, 12(1): 1-22.

Kharkova, T.L., and E.M. Andreev (2000). 'Did the Economic Crisis Cause the Fertility Decline in Russia: Evidence from the 1994 Microcensus'. European Journal of Population, 16 (3): 211-33. 
Klasen, S., and A. Launov (2006). 'Analysis of the Determinants of Fertility Decline in the Czech Republic'. Journal of Population Economics, 19: 25-54.

Kohler, H.-P., and I. Kohler (2002). 'Fertility Decline in Russia in the Early and Mid 1990s: The Role of Economic Uncertainty and Labour Market Crises’. European Journal of Population, 18: 233-62.

Kristenson, M., B. Zieden, Z. Kucinskiene, et al. (1997). 'Antioxidant State and Mortality from Coronary Heart Disease in Lithuanian and Swedish Men: Concomitant Cross Sectional Study of Men Aged 50'. British Medical Journal, 314: 629-33.

Leon, D.A., L. Saburova, S. Tomkins, E. Andreev, N. Kiryanov, M. McKee and V.M. Shkolnikov (2007). 'Hazardous Alcohol Drinking and Premature Mortality in Russia: A Population Based Case-Control Study’. The Lancet, 369: 2001-9.

Levine, P.B., and D. Staiger (2004). 'Abortion Policy and Fertility Outcomes: The Eastern European Experience’. Journal of Law and Economics, April: 223-43.

Lokshin, M. (2005). 'Household Childcare Choices and Women's Work Behavior in Russia’. The Journal of Human Resources, 39(4): 1094-115.

Lorentzen, P., J. McMillan, and R. Wacziarg (2008). 'Death and Development'. Journal of Economic Growth, 13: 81-124.

Malyutina, S., M. Bobak, S. Kurilovitch, V. Gafarov, G. Simonova, Y. Nikitin, and M. Marmot (2002). 'Relation between heavy and binge drinking and all-cause and cardiovascular mortality in Novosibirsk, Russia: a prospective cohort study’, The Lancet, 360: 1448-54.

McKee, M. and A. Britton (1998). 'The Positive Relationship Between Alcohol and Heart Disease in Eastern Europe: Potential Physiological Mechanisms'. Journal of the Royal Society of Medicine, 91: 402-407.

McKee, M., S. Süzcs, A. Sárváry, R. Ádany, N. Kiryanov, L. Saburova, S. Tomkins, E. Andreev, and D.A. Leon (2005). 'The Composition of Surrogate Alcohols Consumed in Russia'. Alcoholism: Clinical and Experimental Research, 29(10): 1884-8.

Meslé, F., J. Vallin, and I. Badurashvili (2007). 'A Sharp Increase in Sex Ratio at Birth in the Caucasus. Why? How?’. In I. Attané and C.Z. Guilmoto (eds) Watering the Neighbour's Garden: The Growing Demographic Female Deficit in Asia. Committee for International Co-operation in National Research in Demography: Paris.

Osili, U.O., and B.T. Long, (2008). 'Does Female Schooling Reduce Fertility? Evidence from Nigeria'. Journal of Development Economics, 87(1): 57-75.

Perelli-Harris, B. (2005). 'The Path to Lowest-Low Fertility in Ukraine'. Population Studies, 59(1): 55-70.

Perelli-Harris, B. (2006). 'The Influence of Informal Work and Subjective Well-Being on Childbearing in Post-Soviet Russia'. Population and Development Review, 32(4): 729-53. 
Popova, S., J. Rehm, J. Patra, and W. Zatonski (2007) 'Comparing Alcohol Consumption in Central and Eastern Europe to Other European Countries'. Alcohol \& Alcoholism, 42(5): 465-73.

Puska, P., T. Matilainen, P. Jousilahti, et al. (1993). 'Cardiovascular Risk Factors in the Republic of Karelia, Russia, and in North Karelia, Finland'. International Journal of Epidemiology, 22(6): 1048-55.

Shkolnikov, V., M. McKee, and D.A. Leon (2001). 'Changes in Life Expectancy in Russia in the mid 1990s'. The Lancet 357: 917-21.

Stegmayr, B., T. Vinogradova, S. Malyutina, M. Peltonen, Y. Nikitin, K. Asplund (2000). 'Widening Gap of Stroke Between East and West: Eight-Year Trends in Occurrence and Risk Factors in Russia and Sweden’. Stroke, January: 2-8.

Stillman, S. (2006). 'Health and Nutrition in Eastern Europe and the Former Soviet Union during the Decade of Transition: A Review of the Literature'. Economics and Human Biology, 4: 104-46.

Sobotka, T. (2003). 'Re-Emerging Diversity: Rapid Fertility Change in Central and Eastern Europe After the Collapse of the Communist Regimes'. Population (English Edition), 58(4/5): 451-85.

Treisman, D. (2008). 'Pricing Death: The Political Economy of Russia's Alcohol Crisis'. Mimeo.

Westoff, C.F. (2005). 'Recent Trends in Abortion and Contraception in 12 Countries'. Demographic and Health Surveys Analytical Studies, 8.

Young, A. (2005). 'The Gift of the Dying: The Tragedy of AIDS and the Welfare of Future African Generations’. Quarterly Journal of Economics, 120(2): 423-66.

Zaridze, D., D. Maximovitch, A. Lazarev, V. Igitov, A. Boroda, J. Boreham, P. Boyle, R. Peto, and P. Boffetta (2009a). 'Alcohol Poisoning is a Main Determinant of Recent Mortality Trends in Russia: Evidence from a Detailed Analysis of Mortality Statistics and Autopsies’. International Journal of Epidemiology, 38: 143-53.

Zaridze, D., P. Brennan, J. Boreham, A. Boroda, R. Karpov, A. Lazarev, I. Konobeevskaya, V. Igitov, T. Terechova, P. Boffetta, and R. Peto (2009b). 'Alcohol and Cause-Specific Mortality in Russia: A Retrospective Case-Control Study of 48,557 Adult Deaths’. The Lancet, 373: 2201-14.

Zatonski, W.A., A.J. McMichael, and J.W. Powles (1998). 'Ecological Study of Reasons for Sharp Decline in Mortality from Ischaemic Heart Disease in Poland since 1991’. British Medical Journal, 316(4): 1047-51.

Zatonski, W.A., H. Campos, and W. Willett, (2008). 'Rapid Declines in Coronary Heart Disease Mortality in Eastern Europe Are Associated with Increased Consumption of Oils Rich in Alpha-Linolenic Acid'. European Journal of Epidemiology, 23: 3-10. 